\title{
Fengycin or plipastatin? A confusing question in Bacilli
}

\author{
WALAA HUSSEIN \\ The Genetics and Cytology Department, Genetic Engineering and Biotechnology Division, National Research Center, Dokki, Giza, Egypt
}

\begin{abstract}
According to most of the related literature published since their discovery in 1986, fengycin and plipastatin are very related molecules. These are lipodecapeptides encoded by operons of five synthetase genes. The most important difference between these two molecules lies in the peptide moiety at the position of the D-tyrosine, which is encoded by the second gene $f e n B$ of fengycin operon and by the fourth gene $p p s D$ of plipastatin operon. Here, we aimed to differentiate between fengycin and plipastatin molecules. We designed degenerate primers using the consensus sequence of the epimerization domain responsible for the transformation of L-tyrosine to D-tyrosine from Bacillus subtilis 168, Bacillus amyloliquefaciens FZB42, and Bacillus atrophaeus 1942. These degenerate primers were then used to amplify fragments from B. amyloliquefaciens S499, B. subtilis ATCC 21332, and Bacillus cereus. Alignment of the sequences of the amplified fragments with the sequences from the mentioned strains deposited in GenBank database showed high similarity with 64 B. subtilis strains, 24 B. amyloliquefaciens strains, seven B. atrophaeus strains, one B. cereus strain, one Bacillus sonorensis strain, two Bacillus methylotrophicus strains, and 45 Bacillus velezensis strains. The results confirmed that these Bacillus strains harborthe tyrosine epimerization domain located on the fourth gene of their fengycin or plipastatin operons, which indicated that these strains synthesize plipastatin rather than fengycin.
\end{abstract}

Key words: fengycin, plipastatin, Bacilli, epimerization domain, NRPS

\section{Introduction}

Fengycins and plipastatins are closely related lipodecapeptides produced by various species of Bacillus, namely Bacillus subtilis, Bacillus amyloliquefaciens, Bacillus globigii, and Bacillus cereus (Schneider et al., 1999; Volpon et al., 2000; Vater et al., 2002; Williams et al., 2002; Bie et al., 2009; Pyoung et al., 2010). These molecules are synthesized by the nonribosomal peptides system (NRPS), which is a multienzyme system consisting of an arrangement of modules. The enzymatic units that reside within a module are called domains. Each module contains three domains: an adenylation (A) domain for substrate recognition, a peptidyl carrier protein (PCP) domain to hold the activated substrate, and a condensation (C) domain to form peptide bonds (Dieckmann et al., 1995; Stachelhaus and Marahiel, 1995; Stachelhaus et al., 1996; Mootz and Marahiel, 1997; Stachelhaus et al., 1998; Ehmann et al., 2000; May et al., 2001; Bergendahl et al., 2002).
Based on the amino acid residue present at position 6 , fengycin and plipastatin may have any of the two structures: form A (Ala) or form B (Val). In the structure of these molecules, the peptidic moiety has an internal lactone ring between the carboxyl group of the terminal amino acid (Ile) and the hydroxyl group of the tyrosine residue at position 3 . The $\beta$-hydroxy fatty acid chains at C14-C18 positions are linked to the N-terminal amino acid residue (Glu) via an amide bond (Vanittanakom et al., 1986; Nishikiori et al., 1986b). The fatty acid chains at $\mathrm{C} 15, \mathrm{C} 16$, and $\mathrm{C} 17$ positions are the main representatives and are saturated, except in the case of the lipopeptide isolated from Bacillus thuringiensis which has a fatty acid chain with a double bond between C13 and C14 (Kim et al., 2004). The structure of the lipodecapeptide plipastatin from B. cereus BMG302fF67 was first described by Nishikiori et al. (1986a). Based on the structure, plipastatins are divided into two groups: group A and group B. Group A plipastatins have

\footnotetext{
* Corresponding author: The Genetics and Cytology Department, Genetic Engineering and Biotechnology Division, National Research Center, Dokki, Giza, Egypt; e-mail: nourwalaa@hotmail.com
} 
Plipastatin operon

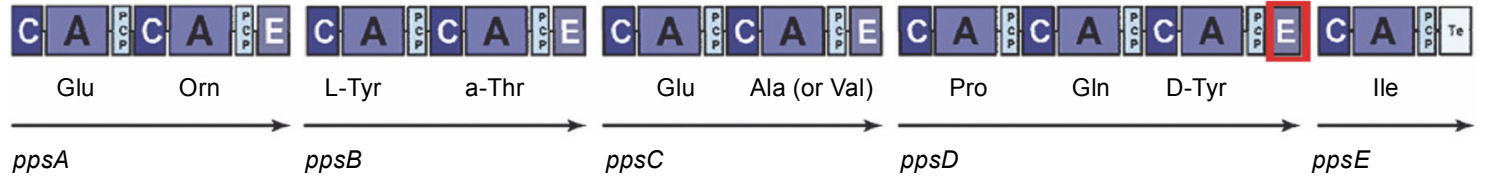

Fengycin operon

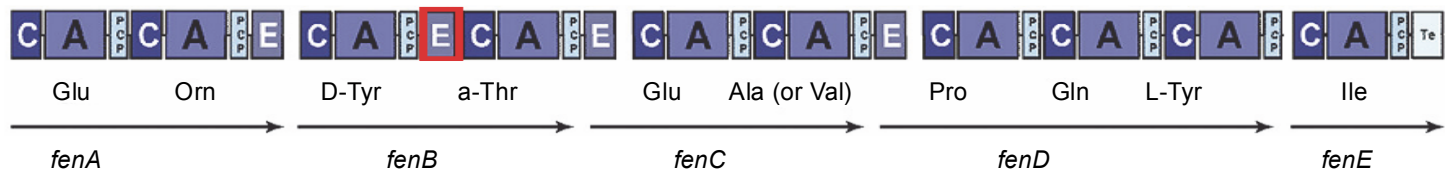

Fig. 1. The organization of plipastatin and fengycin operon and the differences in peptide structures as reported by Ongena and Jacques (2008); D-tyrosine is located on pps $D$ gene at position 9 (amino acid) in plipastatin, whereas it is located on fenD gene at position 3 in fengycin

D-Ala at the sixth position of the amino acid sequence from the $\mathrm{N}$-terminus, whereas group B plipastatins have $\mathrm{D}$ Val. The plipastatins numbered ' 1 ' 1 (A1 and B1) have 3(R)-hydroxyhexadecanoic acid (B-hydroxypalmitic acid) as the fatty acid residue, whereas those numbered ' 2 ' 2 (A2 and B2) have 14(S)-methyl-3(R)-hydroxyhexadecanoic acid (B-hydroxy-anteiso-palmitic acid) as the fatty acid residue.

Electrospray ionization/collision-induced dissociation mass spectrometry was used in a study to analyze the fengycin homologues produced by $B$. subtilis JA (Wang et al., 2004). The $L$ and $D$ forms of tyrosine and the presence of a Gln residue instead of a Glu at position 8 were found to constitute the differences between fengycin and plipastatin. The $\mathrm{L}$ and $\mathrm{D}$ forms of tyrosine were found at positions 3 and 9 for plipastatins, respectively, whereas they were found at positions 9 and 3 for fengycins (Wang et al., 2004) (Fig. 1). However, Schneider et al. (1999) detected a fengycin molecule with a D-Tyr at position 3 from the supernatant of the culture of $B$. subtilis S499. This result could be correlated with the findings on the structure of the synthetases described for other fengycin- or plipastatin-producing strains.

Bacillus subtilis 168 was the first strain in which the operon encoding fengycin or plipastatin synthetases was described (Tosato et al., 1997); five synthetase-encoding genes ( $p p s A B C D E$ ) were reported in this strain. Wu et al. (2007) reported that in $B$. subtilis F29-3 strain five genes encoding fengycin synthetases were present in fenCDEAB order. The other plipastatin or fengycin synthetases were described in B. subtilis b213 and A1/3 (Steller et al., 2000). The authors reported that the operon was a cluster of five genes (fen 1-5) which showed a high homology to the pps and fen genes from $B$. subtilis strains 168 and F29-3. Finally, in B. amyloliquefaciens FZB42, Koumoutsi et al. (2004) reported that the organization and location of fengycin (fen) operon were similar to B. subtilis 168 .

Plipastatins are reported to act as inhibitors of phospholipase A2, an enzyme involved in various important physiological cellular functions such as inflammation, acute hypersensitivity, and blood platelet aggregation (Umezawa et al., 1986). Fengycins are known to act as strong fungitoxic agents against various filamentous fungi such as Botrytis cinerea, Colletotrichum acutatum, Monilinia fructicola, Monilinia hiemalis, Paecilomyces variotii, Pyricularia oryzae, Rhizoctonia solani, Schizophyllum commune, Fusarium moniliforme Sheldon ATCC 38932, and Colletotrichum gloeosporioides (Vanittanakom et al., 1986; Sun et al., 2006; Romero et al., 2007; Hu et al., 2007; Bie et al., 2009; Pyoung et al., 2010).

Here, we aimed to differentiate between fengycin and plipastatin based on the position of tyrosine epimerization domain in the second and fourth genes of the operon using degenerate primers for polymerase chain reaction (PCR) and NRPS predictor software for analyzing the multi-domain synthetases involved in the biosynthesis of fengycin and plipastatin from different Bacillus strains.

\section{Materials and methods}

\section{Bacterial strains}

The Bacillus species and Escherichia coli strains used in this study were grown aerobically in Luria-Bertani medium at $37^{\circ} \mathrm{C}$ (Table 1 ). 
Table 1. Bacterial strains and plasmids used in this study

\begin{tabular}{|c|c|c|}
\hline Bacterial strains & Description & Source \\
\hline B. subtilis ATCC 21332 & wild type & ProBioGEM \\
\hline B. amyloliquefaciens $\mathrm{S} 499$ & wild type & ProBioGEM \\
\hline B. amyloliquefaciens FZB42 & wild type & ProBioGEM \\
\hline B. subtilis 168 & $\operatorname{trpC} C^{2}, \operatorname{sfp}^{0}$ & lab stock \\
\hline B. cereus & wild type & lab stock \\
\hline E. coli DH5 $\alpha$ & $\begin{array}{l}\mathrm{F}^{-} \text {endA1 glnV44 thi-1 recA1 relA1 gyrA96 deoR nupG purB20 } \\
\varphi 80 \mathrm{~d} l a c Z \Delta \mathrm{M} 15 \Delta(\text { lacZYA-argF }) \mathrm{U} 169, \text { hsdR17 }\left(r_{K}^{-} m_{K}^{+}\right), \lambda^{-}\end{array}$ & lab stock \\
\hline Plasmids & Description & Source \\
\hline pGEM-T Easy & cloning vector, $\mathrm{Ap}^{\mathrm{r}}$ & lab stock \\
\hline pMG113 & $\begin{array}{l}1670 \text { bp fenD (Ep) fragment of Bacillus subtilis ATCC } 21332 \text { cloned } \\
\text { into pGEM-T Easy }\end{array}$ & this study \\
\hline pMG114 & 1651 bp fenD (Ep) fragment of Bacillus cereus into pGEM-T Easy & this study \\
\hline pMG115 & $\begin{array}{l}1641 \text { bp fenD (Ep) fragment of Bacillus amyloliquefaciens S499 cloned } \\
\text { into pGEM-T Easy }\end{array}$ & this study \\
\hline pMG116 & $\begin{array}{l}1446 \text { bp fenB fragment of Bacillus subtilis ATCC } 21332 \text { cloned } \\
\text { into pGEM-T Easy }\end{array}$ & this study \\
\hline pMG117 & $\begin{array}{l}1449 \text { bp fenB fragment of Bacillus amyloliquefaciens S499 cloned } \\
\text { into pGEM-T Easy }\end{array}$ & this study \\
\hline pMG118 & $1447 \mathrm{bp}$ fenB fragment of Bacillus cereus into pGEM-T Easy & this study \\
\hline
\end{tabular}

ProBioGEM - Laboratoire des Procédés Biologiques, Génie Enzymatique et Microbien, France

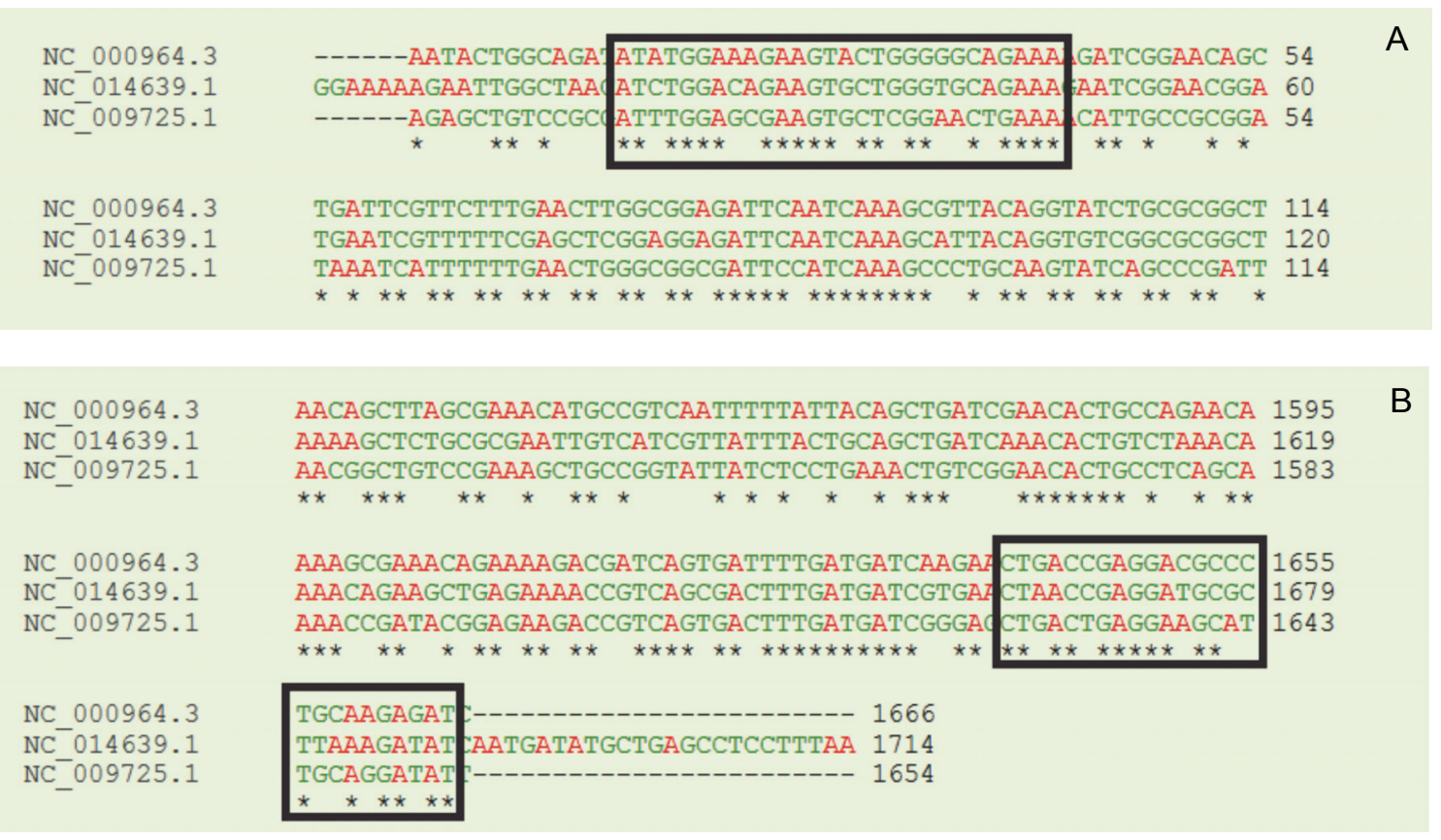

Fig. 2. ClustalW2 multiple-sequence alignment of tyrosine epimerization domain of fengycin (plipastatin) synthetase D of Bacillus subtilis 168, Bacillus atrophaeus 1942, and Bacillus amyloliquefaciens FZB42 (position 9); sequence "A" refers to the consensus sequence used for designing the forward primer, while sequence "B" refers to the consensus sequence used for designing the reverse primer 


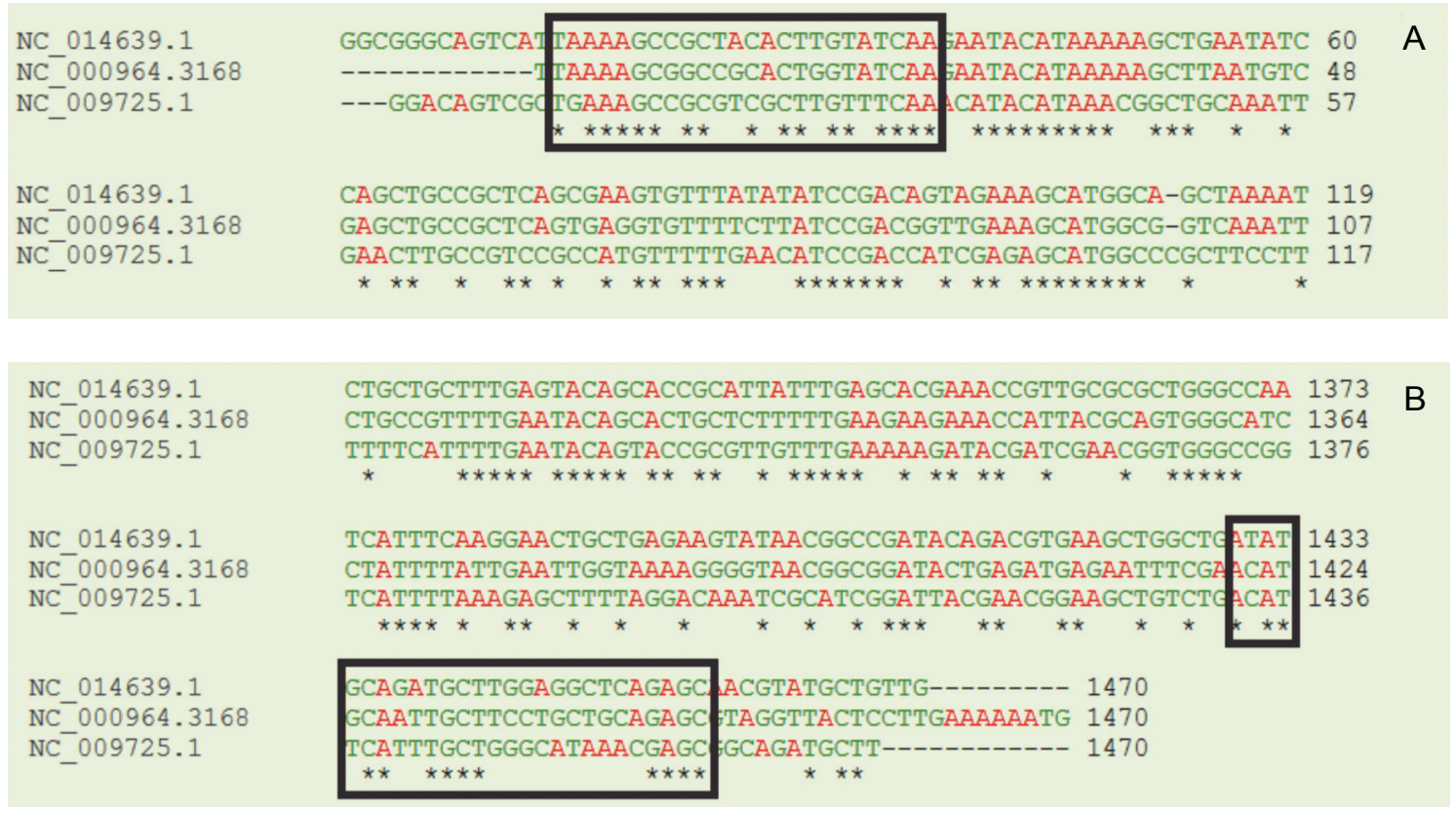

Fig. 3. ClustalW2 multiple-sequence alignment of the tyrosine thiolation domain and the threonine adenylation domain of fengycin (plipastatin) synthetase B of Bacillus atrophaeus 1942, Bacillus subtilis 168, and Bacillus amyloliquefaciens FZB42 (position 3); sequence "A" refers to the consensus sequence used for designing the forward primer, while sequence "B" refers to the consensus sequence used for designing the reverse primer

Table 2. Degenerate primers designed to detect the tyrosine epimerization domain from Bacillus species

\begin{tabular}{l|l|c}
\hline \multicolumn{1}{c|}{ Primer name } & \multicolumn{1}{|c}{ Primer sequence $\left(5^{\prime}-3^{\prime}\right)$} & Fragment size \\
\hline$E p$ fwd & $5^{\prime}$-TRAAAGCSGCBDCRCTKGTWTCAA-3' & \multirow{2}{*}{$1641-1670 \mathrm{bp}$} \\
\cline { 1 - 2 }$E p$ rev & $5^{\prime}$-AYATKCADWTGCTKSSHRBHDMMGAGC-3' & \\
\cline { 1 - 2 }$f e n B$ fwd & $5^{\prime}$-ATHTGCAVMGAAGTRCTSGGDRCWGAAA-3' & \multirow{2}{*}{ 1443-1449 bp } \\
\cline { 1 - 2 }$f e n B$ rev & $5^{\prime}$-CTRACYGAGGAHGCVYTKMARGAKAT-3' & \\
\hline
\end{tabular}

\section{Degenerate primers design and PCR conditions}

The sequences used for designing the degenerate primers were taken from GenBank. Among the primers, two pairs were designed manually using the IUPAC symbols for degenerate bases based on the consensus sequence of the epimerization domain. These primers were designed to recognize the tyrosine epimerization domain at position 9 (fenD or $p p s D$ ) but not at position 3 (fenB or $p p s B$ ). The first pair of primers $(E p)$ was designed based on the consensus sequence obtained from the alignment of the sequences of epimerization domain (Ep domain) of fenD from B. amyloliquefaciens FZB42, ppsD from B. subtilis 168, and Bacillus atrophaeus 1942 (Fig. 2 and Table 2).

The second pair of primers $f e n B$ was designed based on the consensus sequence obtained from the alignment of the sequences from $B$. amyloliquefaciens FZB42, $p p s B$ from $B$. subtilis 168, and B. atrophaeus 1942 (Fig. 3). These primers were designed to detect whether there is a tyrosine epimerization domain prior to the adenylation domain of threonine in any of the Bacillus strains tested in the study.

The genomic DNA was isolated from the strains using DNA purification kit (Wizard $\AA$ Genomic, Promega) according to the manufacturer's instructions. The PCR conditions used in this study were as follows: initial denaturation step at $94^{\circ} \mathrm{C}$ for $2 \mathrm{~min}$, followed by $35 \mathrm{cy}$ cles of denaturation step at $94{ }^{\circ} \mathrm{C}$ for $45 \mathrm{sec}$, annealing step at $50^{\circ} \mathrm{C}$ for $30 \mathrm{sec}$, and elongation step at $72^{\circ} \mathrm{C}$ for 1.5 min. Following PCR, the gels were photographed using Gel Doc ${ }^{\mathrm{TM}} \mathrm{XR}+$ Gel Documentation System (BioRad). 


\section{Extraction of PCR products from agarose gel}

Following amplification, the fragments were extracted and purified using Zymoclean ${ }^{\circledR}$ Gel DNA Recovery Kit (Epigenetics Company) according to the manufacturer's instructions.

\section{PCR products ligation}

The PCR fragments obtained from strains $B$. subtilis 168 and $B$. subtilis ATCC 21332 , and B. amyloliquefaciens FZB42 and $B$. amyloliquefaciens S499 were ligated to pGEM-T Easy as described in the technical manual of pGEM ${ }^{\circledR}-\mathrm{T}$ and pGEM ${ }^{\circledR}$-T Easy Vector Systems from QIAGEN.

\section{Cloning and transformation protocol}

Cloning and transformation was performed as described in the technical manual of pGEM ${ }^{\circledR}-\mathrm{T}$ and pGEM ${ }^{\circledR}-\mathrm{T}$ Easy Vector Systems from QIAGEN. The procedure used was as follows: $2 \mu \mathrm{l}$ of ligation reaction was added to a sterile $(17 \times 100 \mathrm{~mm})$ polypropylene tube or a $1.5 \mathrm{ml}$ microcentrifuge tube and kept on ice. Another tube with $0.1 \mathrm{ng}$ uncut plasmid was set up on ice to determine the transformation efficiency of the competent $E$. coli $\mathrm{DH} 5 \alpha$ cells prepared in the laboratory (Tang et al., 1994).

\section{Results}

\section{Epimerization domain detection by degenerate primers}

Using epimerization domain primers $(E p)$ and $f e n B$ primers, the fragments of expected sizes were amplified by PCR. All strains used for the detection of epimerization domain are listed in Table 2 . The epimerization domain primers $(E p)$ amplified one fragment from all tested Bacillus strains: a fragment of 1670 bp from $B$. subtilis 168 and $B$. subtilis ATCC 21332 and a fragment of 1641 bp from $B$. amyloliquefaciens FZB42 and B. amyloliquefaciens S499; one fragment of $1651 \mathrm{bp}$ was amplified from $B$. cereus.

The fen $B$ primers also amplified one fragment from all tested Bacillus strains: a fragment of $1446 \mathrm{bp}$ from $B$. subtilis 168 and $B$. subtilis ATCC 21332 and a fragment of 1449 bp from B. amyloliquefaciens FZB42 and B. amyloliquefaciens S499; one fragment of 1447 bp was amplified from B. cereus.

\section{Alignment of the epimerization domain sequence with sequence in GenBank database}

The fragments amplified by PCR using degenerate primers were cloned and subjected to sequencing. The sequences of fragments were aligned on BLAST website (NCBI database). Only B. subtilis ATCC 21332 fragments submitted to GenBank and obtained these accession numbers ( $p p s D$ partial gene accession number: KX371639.1 and $p p s B$ partial gene accession number: KX371637.1, GenBank). Importantly, the complete genome sequences of $B$. amyloliquefaciens $\mathrm{S} 499$ and $B$. cereus were found deposited in GenBank. The results of alignment with sequences from GenBank revealed that the genomes of 144 Bacillus strains harbor fengycin operon with the tyrosine epimerization domain at position 9 which has been shown in the literature as encoding plipastatin and not fengycin. The $64 \mathrm{~B}$. subtilis strains which harbor tyrosine epimerization domain at position $9(f e n D$ or $p p s D)$ are listed in Table 3 , and the $80 \mathrm{Ba}$ cillus strains, including $24 \mathrm{~B}$. amyloliquefaciens strains, seven $B$. atrophaeus strains, one $B$. cereus strain, one Bacillus sonorensis strain, two Bacillus methylotrophicus strains, and 45 Bacillus velezensis strains, which harbor the tyrosine epimerization domain at position 9 $(f e n D$ or $p p s D)$ are listed in Table 4.

The epimerization domain catalyzes the epimerization of L-tyrosine of the growing polypeptide chain of fengycin or plipastatin. The NRPS predictor (Brian et al., 2009) identified six important residue positions or sequences of the epimerization domain known as the signature or code. These six sequences were all identified in the protein sequences of the epimerization domain of three strains, namely B. cereus, B. subtilis ATCC 21332 , and $B$. amyloliquefaciens S499 (Fig. S1 in supplementary materials).

The alignment of sequences of the epimerization domain Ep (fenD) and fenB of $B$. subtilis ATCC 21332 showed $99 \%$ similarity with $B$. subtilis 168 and $B$. subtilis NCIB 3610. The sequences of Ep (partial fenD) and partial fenB from B. subtilis ATCC 21332 are shown in Figure $\mathrm{S} 2$ in supplementary materials.

The alignment of sequences of the epimerization domain Ep (fenD) and fenB of B. cereus showed 100\% similarity with $B$. cereus MBGJa3 strain and $93 \%$ similarity with $B$. subtilis 168 strain. The sequences of $\mathrm{Ep}$ (partial fenD) and partial fen $B$ from $B$. cereus are shown in Figure S3 in supplementary materials.

The alignment of sequences of the epimerization domain Ep (partial fenD) and partial fenB of $B$. amyloliquefaciens $\mathrm{S} 499$ revealed $99 \%$ similarity with $B$. amyloliquefaciens IT-45 and 97\% similarity with $B$. amylolique- 
Table 3. The list of Bacillus subtilis strains harboring the tyrosine epimerization domain of fengycin at position 9 based on BLAST alignment

\begin{tabular}{|c|c|c|c|}
\hline Description & Accession & Description & Accession \\
\hline Bacillus subtilis subsp. subtilis str. 168 & СР019663.1 & Bacillus subtilis strain GQJK2 & СР020367.1 \\
\hline Bacillus subtilis F29-3 & $\mathrm{AF} 023464.2$ & Bacillus subtilis strain $S G 6$ & СР009796.1 \\
\hline Bacillus subtilis subsp. subtilis strain NCD-2 & CP023755.1 & Bacillus subtilis strain TLO3 & CP021169.1 \\
\hline Bacillus subtilis strain $\mathrm{SX01705}$ & СР022287.1 & Bacillus subtilis BSn5 & CP002468.1 \\
\hline Bacillus subtilis subsp. subtilis strain BSD-2 & CP013654.1 & Bacillus subtilis subsp. subtilis strain D12-5 & CP014858.1 \\
\hline Bacillus subtilis HJ5 & СР007173.1 & Bacillus subtilis subsp. subtilis str. BSP1 & СР003695.1 \\
\hline Bacillus subtilis subsp. subtilis str. $B A B-1$ & СР004405.1 & Bacillus subtilis strain BS16045 & СР017112.1 \\
\hline Bacillus subtilis $X F-1$ & CP004019.1 & $\begin{array}{l}\text { Bacillus subtilis subsp. subtilis strain } \\
\text { SRCM101392 }\end{array}$ & CP021921.1 \\
\hline Bacillus subtilis strain BJ3-2 & СР025941.1 & Bacillus subtilis subsp. inaquosorum strain DE111 & СР013984.1 \\
\hline Bacillus subtilis strain HJO-6 & CP016894.1 & Bacillus subtilis strain CW14 & CP016767.1 \\
\hline Bacillus subtilis subsp. subtilis str. OH 131.1 & CP007409.1 & Bacillus subtilis strain ATCC 19217 & CP009749.1 \\
\hline Bacillus subtilis strain VV2 & $\mathrm{CP} 017676.1$ & Bacillus subtilis subsp. subtilis strain $168 G$ & СР016852.1 \\
\hline Bacillus subtilis strain ge28 & CP021903.1 & Bacillus subtilis subsp. subtilis strain KCTC 3135 & СР015375.1 \\
\hline $\begin{array}{l}\text { Bacillus subtilis subsp. subtilis strain } \\
\text { SRCM100761 }\end{array}$ & CP021889.1 & Bacillus subtilis subsp. subtilis strain delta6 & CP015975.1 \\
\hline $\begin{array}{l}\text { Bacillus subtilis subsp. subtilis strain } \\
\text { SRCM100757 }\end{array}$ & СР021499.1 & Bacillus subtilis strain SZMC $6179 \mathrm{~J}$ & CP015004.1 \\
\hline $\begin{array}{l}\text { Bacillus subtilis subsp. subtilis strain } \\
\text { SRCM101444 }\end{array}$ & СР021498.1 & Bacillus subtilis strain ATR2 & CP018133.1 \\
\hline Bacillus subtilis subsp. subtilis RO-NN-1 & CP002906.1 & Bacillus subtilis subsp. subtilis strain CU1050 & СР014166.1 \\
\hline Bacillus subtilis strain TLO3 & CP023257.1 & Bacillus subtilis strain TO-A JP & CP011882.1 \\
\hline Bacillus subtilis TOA & СР005997.1 & Bacillus subtilis KCTC 1028 & CP011115.1 \\
\hline Bacillus subtilis subsp. subtilis str. AG1839 & CP008698.1 & Bacillus subtilis subsp. subtilis strain $3 N A$ & CP010314.1 \\
\hline $\begin{array}{l}\text { Bacillus subtilis subsp. subtilis str. JH642 substr. } \\
\text { AG174 }\end{array}$ & CP007800.1 & Bacillus subtilis strain PS832 & CP010053.1 \\
\hline Bacillus subtilis PY79 & CP006881.1 & Bacillus subtilis strain HRBS-10TDI13 & CP015222.1 \\
\hline Bacillus subtilis subsp. subtilis $6051-H G W$ & CP003329.1 & Bacillus subtilis strain KH2 & CP018184.1 \\
\hline Bacillus subtilis subsp. globigii strain ATCC 49760 & CP014840.1 & Bacillus subtilis strain $29 R 7-12$ & CP017763.1 \\
\hline Bacillus subtilis strain UD1022 & CP011534.1 & Bacillus subtilis strain Bs-115 & CP020722.1 \\
\hline Bacillus subtilis strain BS38 & СР017314.1 & $\begin{array}{l}\text { Bacillus subtilis subsp. subtilis strain } \\
\text { SRCM100333 }\end{array}$ & СР021892.1 \\
\hline Bacillus subtilis subsp. natto strain CGMCC 2108 & CP014471.1 & Bacillus subtilis strain $D K U_{-} N T_{-} 02$ & CP022890.1 \\
\hline Bacillus subtilis subsp. natto BEST195 & AP011541.2 & Bacillus subtilis strain $D K U_{-} N T_{-} 03$ & CP022891.1 \\
\hline Bacillus subtilis strain $S R 1$ & CP021985.1 & Bacillus subtilis strain QST713 & DQ011337.1 \\
\hline Bacillus subtilis subsp. subtilis strain QB5412 & СР017312.1 & Bacillus subtilis strain $M B 14$ & KF524437.1 \\
\hline Bacillus subtilis strain NCIB 3610 & CP020102.1 & Bacillus subtilis strain $B-1$ & CP009684.1 \\
\hline Bacillus subtilis strain Bs-916 & CP009611.1 & Bacillus subtilis strain J-5 & CP018295.1 \\
\hline
\end{tabular}


Table 4. The list of Bacillus strains harboring the tyrosine epimerization domain of fengycin at position 9 based on BLAST alignment

\begin{tabular}{|c|c|c|c|}
\hline Description & Accession & Description & Accession \\
\hline Bacillus amyloliquefaciens $C C 178$ & CP006845.1 & Bacillus velezensis strain $S Y B C H 47$ & CP017747.1 \\
\hline Bacillus amyloliquefaciens subsp. plantarum str. FZB42 & СР000560.1 & Bacillus velezensis strain YJ11-1-4 & СР011347.1 \\
\hline Bacillus amyloliquefaciens subsp. plantarum UCMB5113 & HG328254.1 & Bacillus velezensis $S Q R 9$ & CP006890.1 \\
\hline Bacillus amyloliquefaciens subsp. plantarum UCMB5033 & HG328253.1 & Bacillus velezensis strain $S C G B 1$ & СP023320.1 \\
\hline Bacillus amyloliquefaciens subsp. amyloliquefaciens KHG19 & СР007242.1 & Bacillus velezensis strain $S C D B 291$ & СР022654.2 \\
\hline Bacillus amyloliquefaciens strain B15 & СР014783.1 & Bacillus velezensis strain $9 D-6$ & CP020805.1 \\
\hline Bacillus amyloliquefaciens UMAF6639 & CP006058.1 & Bacillus velezensis strain CCO9 & CP015443.1 \\
\hline Bacillus amyloliquefaciens subsp. plantarum NAU-B3 & HG514499.1 & Bacillus velezensis strain $S C G B 574$ & CP023431.1 \\
\hline Bacillus amyloliquefaciens strain $Q-426$ fenEDCBA & JQ271536.1 & Bacillus velezensis strain $C M T-6$ & CP025341.1 \\
\hline Bacillus amyloliquefaciens $Y 2$ & СР003332.1 & Bacillus velezensis strain J01 & CP023133.1 \\
\hline Bacillus amyloliquefaciens $C C 178$ & СР006845.1 & Bacillus velezensis strain T20E-257 & CP021976.1 \\
\hline Bacillus amyloliquefaciens subsp. plantarum YAU B9601-Y2 & HE774679.1 & Bacillus velezensis strain $Z L 918$ & СР021338.1 \\
\hline Bacillus amyloliquefaciens UMAF6614 & СР006960.1 & Bacillus velezensis strain GQJK49 & CP021495.1 \\
\hline Bacillus amyloliquefaciens subsp. plantarum UCMB5036 & HF563562.1 & Bacillus velezensis strain JTYP2 & CP020375.1 \\
\hline Bacillus amyloliquefaciens LFB112 & СР006952.1 & Bacillus velezensis strain sx01604 & CP018007.1 \\
\hline Bacillus amyloliquefaciens strain WS-8 & СР018200.1 & Bacillus velezensis strain 157 & CP022341.1 \\
\hline Bacillus amyloliquefaciens strain $Y 14$ & CP017953.1 & Bacillus velezensis strain D2-2 & CP014990.1 \\
\hline Bacillus amyloliquefaciens strain $S 499$ & СР014700.1 & Bacillus velezensis strain LS69 & CP015911.1 \\
\hline Bacillus amyloliquefaciens strain LM2303 & CP018152.1 & Bacillus velezensis strain $S 3-1$ & CP016371.1 \\
\hline Bacillus amyloliquefaciens IT-45 & СР004065.1 & Bacillus velezensis strain CBMB205 & CP014838.1 \\
\hline Bacillus amyloliquefaciens strain L-S60 & CP011278.1 & Bacillus velezensis $N J N-6$ & CP007165.1 \\
\hline Bacillus amyloliquefaciens strain L-H15 & СР010556.1 & Bacillus velezensis strain GFP-2 & CP021011.1 \\
\hline Bacillus amyloliquefaciens strain MBE128 & СР013727.1 & Bacillus velezensis strain $G H 1-13$ & CP019040.1 \\
\hline Bacillus amyloliquefaciens subsp. plantarum CAU B946 & HE617159.1 & Bacillus velezensis strain JS25R & CP009679.1 \\
\hline Bacillus atrophaeus strain NRS $1221 A$ & СР010778.1 & Bacillus velezensis TrigoCor 1448 & CP007244.1 \\
\hline Bacillus atrophaeus subsp. globigii strain BSS & СР007640.1 & Bacillus velezensis strain JJ-D34 & CP011346.1 \\
\hline Bacillus atrophaeus 1942 & CP002207.1 & Bacillus velezensis strain 10075 & CP025939.1 \\
\hline Bacillus atrophaeus strain SRCM101359 & СР021500.1 & Bacillus vallismortis strain NBIF-001 & CP020893.1 \\
\hline Bacillus atrophaeus strain GQJK17 & СР022653.1 & Bacillus velezensis strain $N K G-1$ & CP024203.1 \\
\hline Bacillus atrophaeus strain BA59 & СР024051.1 & Bacillus velezensis strain SRCM100072 & CP021888.1 \\
\hline Bacillus atrophaeus UCMB-5137 & СР011802.1 & Bacillus velezensis strain Lzh-a42 & CP025308.1 \\
\hline Bacillus cereus strain MBGJa3 c & СР026523.1 & Bacillus velezensis strain $\mathrm{CNO} 26$ & СР024897.1 \\
\hline Bacillus methylotrophicus strain CBMB205 & CP011937.1 & Bacillus velezensis $S 141$ & AP018402.1 \\
\hline Bacillus methylotrophicus strain B25 & LN999829.1 & Bacillus velezensis strain $O S Y-S 3$ & CP024706.1 \\
\hline Bacillus sonorensis strain SRCM101395 & СР021920.1 & Bacillus velezensis strain $M 75$ & CP016395.1 \\
\hline Bacillus velezensis strain $9912 D$ & СР017775.1 & Bacillus velezensis strain AGVL-005 & СР024922.1 \\
\hline Bacillus velezensis strain LABIM40 & СР023748.1 & Bacillus velezensis strain TJ02 & CP024797.1 \\
\hline Bacillus velezensis strain $S B 1216$ & CP015417.1 & Bacillus velezensis strain $L-1$ & CP023859.1 \\
\hline Bacillus velezensis AS43.3 & СР003838.1 & Bacillus velezensis strain TB1501 & CP022531.1 \\
\hline Bacillus velezensis strain SRCM101413 & CP021890.1 & Bacillus velezensis strain $D K U_{-} N T_{-} 04$ & CP026533.1 \\
\hline
\end{tabular}


faciens FZB42. The sequences of $\mathrm{Ep}$ (partial fenD) and partial fenB from $B$. amyloliquefaciens $\mathrm{S} 499$ are shown in Figure S4 in supplementary materials.

\section{Discussion}

An analysis of differences in the structure and biological activities revealed the distinction between the two lipodecapeptides fengycin and plipastatin (Jacques, 2011). To date, only a few studies have shown the differences between these two compounds (Nishikiori et al., 1986b; Vanittanakom et al., 1986; Wang et al., 2004). Only two differences were reported in their structure: 1 ) the presence of glutamine instead of glutamic acid at position 8 (this difference has not been mentioned in any other studies); and 2) the presence of $\mathrm{L}$ and $\mathrm{D}$ forms of tyrosine at positions 3 and 9 in plipastatin and positions 9 and 3 in fengycin, respectively (Wang et al., 2004). In this study, we aimed to differentiate plipastatin and fengycin via detecting the presence of the epimerization domain at position 3 or 9 using degenerate primers for PCR. The degenerate primers $E p(f e n D)$ and $f e n B$ designed for the detection of position of the epimerization domain in the five Bacillus strains, namely $B$. subtilis 168 and $B$. subtilis ATCC $21332, B$. cereus, and B. amyloliquefaciens FZB42 and $B$. amyloliquefaciens S499, revealed the presence of the tyrosine epimerization domain at position 9 (fen $D$ or $p p s D$ gene). These findings indicate that plipastatin is synthesized by all the Bacillus strains tested herein.

The alignment of five sequences of the fragments amplified by PCR using degenerate primers from $B$. subtilis ATCC $21332, B$. cereus, and B. amyloliquefaciens S499 on BLAST website (NCBI database) revealed the presence of the epimerization domain at position 9 (ppsD gene). These results are in agreement with the results shown by Hussein et al. (2011) for B. subtilis 168 and $B$. subtilis ATCC 21332 . The authors stated that the organization of the operon from $B$. subtilis ATCC 21332 is similar to that of plipastatin operon from $B$. subtilis 168. Schneider et al. (1999) suggested that understanding the organization of fengycin operon from $B$. subtilis S499 can remove the barriers to differentiating fengycin and plipastatin. They also confirmed the existence of fengycin molecules (with D-tyrosine at position 3 ) in the tested bacterial strain. When studying the organization of fengycin operon in B. subtilis S499, Hussein et al. (2011) confirmed that this strain belongs to B. amylo- liquefaciens species. The fengycin operon of $B$. amyloliquefaciens $\mathrm{S} 499$ was also studied by the authors, but the results did not confirm whether the molecule harbored by this strain was fengycin or plipastatin (Hussein et al., 2011). However, in our study, we confirmed that this strain harbors plipastatin.

The sequence of fengycin operon of $B$. amyloliquefaciens S499 is now available in GenBank, which confirms our investigations about the presence of the epimerization domain at position 9 , indicating that the molecule synthesized by this strain is plipastatin and not fengycin (Puopolo et al., 2016).

\section{Conclusions}

This work confirms the presence of plipastatin in 144 Bacillus strains, most of which were thought to harbor fengycin. The search for the position of tyrosine epimerization domain using degenerate primers revealed that fengycin was never detected in any Bacillus s train or mentioned in any database.

\section{References}

Bergendahl V., Linne U., Marahiel M.A. (2002) Mutational analysis of the $C$ domain in nonribosomal peptide synthesis. Eur. J. Biochem. 269: 620-629.

Bie X., Zhaoxin L., Lu F. (2009) Identification of fengycin homologues from Bacillus subtilis with ESI-MS/CID. J. Microb. Meth. 79: 272-278.

Bachmann B.O., Ravel J. (2009) In silico prediction of microbial secondary metabolic pathways from DNA sequence data. Meth. Enzymol. 458: 181-217.

Dieckmann R., Lee Y.O., van Liempt H., von Döhren H., Kleinkauf H. (1995) Expression of an active adenylate-forming domain of peptide synthetases corresponding to acyl-CoAsynthetases. FEBS Lett. 357: 212-216.

Ehmann D.E., Shaw-Reid C.A., Losey H.C., Walsh C.T. (2000) The EntF and EntE adenylation domains of Escherichia coli enterobactin synthetase: sequestration and selectivity in acyl-AMP transfers to thiolation domain co-substrates. Proc. Natl. Acad. Sci. 97: 2509-2514.

Hu L.B., Shi ZO., Zhang T., Yang Z.M. (2007) Fengycin antibiotics isolated from B-FSO1 culture inhibit the growth of Fusarium moniliforme Sheldon ATCC38932. FEMS. Microbiol. Lett. 272: 91-98.

Hussein W. (2011) Study on the regulation and biosynthesis of fengycins and plipastatins produced by Bacillus subtilis. www.théses.fr. (online).

Kim P.I., Bai H., Bai D., Chae H., Chung S., Kim Y., Park R., Chi Y.T. (2004) Purification and characterization of a lipopeptide produced by Bacillus thuringiensis CMB26. J. Appl. Microbiol. 97: 942-949. 
Jacques P. (2011) Surfactin and other lipopeptides from Bacillus spp. [in:] Biosurfactants microbiology monographs. Ed. G. Soberon-Chavez. Springer vol. 20, pp. 57-91.

Koumoutsi A., Chen X.H., Henne A., Liesegang H., Hitzeroth G., Franke P., Vater J., Borriss R. (2004) Structural and functional characterization of gene clusters directing nonribosomal synthesis of bioactive cyclic lipopeptides in $\mathrm{Ba}$ cillus amyloliquefaciens strain FZB42. J. Bacteriol. 186: 1084-1096.

May J.J., Wendrich T.M., Marahiel M.A. (2001) The dhb operon of Bacillus subtilis encodes the biosynthetic template for the catecholic siderophore 2,3-dihydroxybenzoate-glycine-threonine trimeric ester bacillibactin. J. Biol. Chem. 276: 7209-7217.

Mootz H.D., Marahiel M.A. (1997) The tyrocidine biosynthesis operon of Bacillus brevis: complete nucleotide sequence and biochemical characterization of functional internal adenylation domains. J. Bacteriol. 179: 6843-6850.

Nishikiori T., Naganawa H., Muraoka Y., Aoyagi T., Umezawa H. (1986a) Plipastatins: new inhibitors of phospholipase A2, produced by Bacillus cereus BMG302-fF67. III. Structural elucidation of plipastatins. J. Antibiot. 39: 755-761.

Nishikiori T., Naganawa H., Muraoka Y., Aoyagi T., Umezawa H. (1986b) The conformational studies on plipastatin A1 by $400 \mathrm{MHZ}$ Proton Magnetic Resonance. J. Antibiot. 6: 860-863.

Puopolo G., Pertot I., Engelen K., Moretto M., Sonego P., Molinatto G., Ongena M. (2016) Direct submission. $\mathrm{CBC}$ /Integrative Genomics, Fondazione Edmund Mach, Via Edmund Mach 1, San Michele All'Adige, Trento 38010, Italy.

Pyoung I. K., Ryu. J., Kim. Y.H., Chi Y.T. (2010) Production of biosurfactant lipopeptides iturin A, fengycin and surfactin from Bacillus subtilis CMB32 for control of Colletotrichum gloespriodes. J. Microbiol. Biotechnol. 20(1): 138-145.

Romero D., Vicente A., Rakotoaly R.H., Dufour S.E., Veening J.W., Arrebola E., Cazorla F.M., Kuipers O., Paquot M., Garcia A.P. (2007) The iturin and fengycin families of lipopeptides are key factors in antagonism of Bacillus subtilis toward Podosphaera fusca. Mol. Plant. Microbe. Interact. 118(2): 323-327.

Schneider J., Taraza K., Budzikiewicza H., Deleu M., Thonart P., Jacques P. (1999) The structure of two Fengycins from Bacillus subtilis S499. Z. Naturforsch. 54c: 859-866.

Stachelhaus T., Marahiel M.A. (1995) Modular structure of peptide synthetases revealed by dissection of the multifunctional enzyme GrsA. J. Biol. Chem. 270: 6163-6169

Stachelhaus T., Hüser A., Marahiel M.A. (1996) Biochemical characterization of peptidyl carrier protein $(P C P)$ the thiolation domain of multifunctional peptide synthetases. Chem. Biol. 3: 913-921.
Stachelhaus T., Mootz H.D., Bergendahl V., Marahiel M.A. (1998) Peptide bond formation in nonribosomal peptide biosynthesis catalytic role of the condensation domain. J. Biol. Chem. 273: 22773-22781.

Steller S., Vater J. (2000) Purification of the fengycin synthetase multienzyme system from Bacillus subtilis b213. J. Chromat. Biomed. Sci. Appl. 14: 267-275.

Sun L., Zhaoxin Lu Z., Bie X., Lu F., Yang S. (2006) Isolation and characterization of a co-producer of fengycins and surfactins, endophytic Bacillus amyloliquefaciens ES-2, from Scutellaria baicalensis Georgi. World J. Microbiol. Biotechnol. 22: 1259-1266.

Tang X., Nakata Y., li H., Zhang M., Gao H., Fujita A., Sakatsume O., Ohta T., Yokoyama T. (1994) The optimization of preparations of competent cells for transformation of $E$. coli. Nucl. Acids Res. 22(14): 2857-2858. doi.org/10.1093/ nar/22.14.2857.

Tosato V., Albertini A.M., Zotti M., Sonda S., Bruschi C.V. (1997) Sequence completion, identification and definition of the fengycin operon in Bacillus subtilis 168. Microbiol. 143: 3443-3450.

Vanittanakom N., Loeffler W., Koch U., Jung G. (1986) Fengycin - a novel antifungal lipopeptide antibiotic produced by Bacillus subtilis F-29-3. J. Antibiot. 7: 888-901.

Vater J., Kablitz B., Wilde C., Franke P., Mehta N., Cameotra S.S. (2002) Matrix asisted laser desorption ionization time of flight mass spectrometry of lipopeptide biosurfactants in whole cells and culture filtrates of Bacillus subtilis C-1 isolated from petroleum sludge. Appl. Environ. Microbiol. 12: 6210-6219.

Volpon L., Besson F., Lancelin J.M. (2000) NMR structure of antibiotics plipastatins $A$ and $B$ from Bacillus subtilis inhibitors of phospholipase A2. FEBS Lett. 485: 76-80.

Umezawa H., Aoyagi T., Nishikiori T., Okuyama A., Yamagishimahamada Y., Takeuchi T. (1986) Plipastatins: new inhibitors of phospholipase A2, produced by Bacillus cereus BMG302-Ff67. I. Taxonomy, production, isolation and preliminary characterization. J. Antibiot. 39: 737-744.

Wang J., Liu W.J., Wang X., Yao J., Yu Z. (2004) Application of electrospray ionization mass spectrometry in rapid typing of fengycin homologues produced by Bacillus subtilis. Lett. Appli. Microbiol. 39: 98-102.

Williams B.H., Hathout Y., Fenselau C. (2002) Structural characterization of lipopeptide biomarkers isolated from Bacillus globoigii. J. Amer. Soc. Mass. Spectrom. 37: 259-264.

Wu C.Y., Chen C.L., Lee Y.H., Cheng Y.C., Wu Y.C., Shu H.Y., Gotz F., Liu S.T. (2007) Nonribosomal synthesis of fengycin on an enzyme complex formed by fengycin synthetases. J. Biol. Chem. 282: 5608-5616. 